$07.2,08.2$

\title{
Изолирующие слои GaN, совместно легированные железом и углеродом
}

\author{
() В.В. Лундин ${ }^{1}$, А.В. Сахаров ${ }^{1}$, Е.Е. Заварин ${ }^{1}$, Д.А. Закгейм ${ }^{1}$, Е.Ю. Лундина ${ }^{1}$, П.Н. Брунков ${ }^{1}$, \\ А.Ф. Цацульников ${ }^{2}$ \\ ${ }^{1}$ Физико-технический институт им. А.Ф. Иофрфе РАН, Санкт-Петербург, Россия \\ ${ }^{2}$ Научно-технологический центр микроэлектроники и субмикронных гетероструктур РАН, Санкт-Петербург, Россия \\ E-mail: lundin.vpegroup@mail.ioffe.ru
}

Поступило в Редакцию 20 февраля 2019г.

В окончательной редакции 11 апреля 2019г.

Принято к публикации 11 апреля 2019г.

Исследованы морфология и электрические свойства полуизолирующих эпитаксиальных слоев GaN. Показано, что улучшение изолирующих свойств слоев при повышении уровня легирования углеродом или железом ограничено ухудшением морфологии, при этом характер развития морфологии различен для этих двух примесей. Установлено, что совместное легирование углеродом и железом позволяет сохранить планарность поверхности $\mathrm{GaN}$ при существенном улучшении изолирующих свойств.

Ключевые слова: транзистор с высокой подвижностью электронов, полуизолирующий нитрид галлия, ток утечки, совместное легирование.

DOI: 10.21883/PJTF.2019.14.48022.17738

При формировании гетероструктур для транзисторов с высокой подвижностью электронов (НЕМТ) на основе III-N соединений одной из ключевых задач является создание изолирующих буферных слоев. Как описано в [1], тонкий слой высокочистого структурносовершенного полупроводника (даже широкозонного) не может эффективно предотвратить утечки, вызванные дрейфом инжектированных электронов в сильных электрических полях. В реальных НЕМТ-структурах на основе $\mathrm{GaN}$ инжекторами электронов могут являться подконтактные области, проводящий канал и даже подложка [2]. По всей видимости, единственным способом подавления утечек в буферных слоях $\mathrm{GaN}$ является введение глубоких центров или за счет легирования соответствующими примесями (углерод, железо), или за счет преднамеренного повышения плотности краевых дислокаций, формирующих глубокие акцепторные уровни [3]. Повышение плотности дислокаций неизбежно ухудшает остальные характеристики приборов, поэтому первый подход представляется более перспективным. Ранее неоднократно сообщалось о возможности легирования GaN углеродом и железом при подаче в реактор соответствующих прекурсоров и получении в результате полуизолирующих слоев $\mathrm{GaN}$ [4-12]. Однако постоянное повышение требований к параметрам транзисторов выдвигает все более высокие требования к изолирующим свойствам буферных слоев $\mathrm{GaN}$, что делает проведение исследований по-прежнему актуальным.

Целью настоящей работы является поиск возможностей дальнейшего улучшения изолирующих свойств эпитаксиальных слоев $\mathrm{GaN}$ для транзисторных применений. Изучались выращенные на подложках $\mathrm{Al}_{2} \mathrm{O}_{3}$ (0001) модельные структуры, состоящие из нижнего контактного слоя $\mathrm{GaN}$ толщиной $2 \mu \mathrm{m}$, легированного кремнием до концентрации $5 \cdot 10^{18} \mathrm{~cm}^{-3}$, и верхнего полуизолирующего слоя GaN. Образцы различались толщиной полуизолирующего слоя, типом легирующей примеси $(\mathrm{C}, \mathrm{Fe})$, уровнем легирования. Структуры выращивались методом газофазной эпитаксии из металлоорганических соединений на установке Dragon-125. Аммиак, триметилгаллий, моносилан, ферроцен, пропан и водород использовались в качестве прекурсоров и несущего газа. После выращивания структуры изучались с помощью оптической и атомно-силовой микроскопии (АСМ) (Dimension 3100 Veeco, CША). Для измерения проводимости полуизолирующих слоев через теневую маску напылялись металлические контакты диаметром $700 \mu \mathrm{m}$ на основе Ti/Au. Сопротивление растекания по слою $n$ $\mathrm{GaN}$ пренебрежимо мало по сравнению с измеряемым сопротивлением полуизолирующего слоя $\mathrm{GaN}$, поэтому второй электрод к слою $n$ - $\mathrm{GaN}$ формировался на краях образцов. Вольт-амперные характеристики (BAX) измерялись с использованием пикоамперметра Keithley 6485. Мы изучали проводимость полуизолирующих слоев $\mathrm{GaN}$ в вертикальном направлении (перпендикулярно плоскости подложки). Проводимость полуизолирующего $\mathrm{GaN}$ в вертикальном и латеральном направлениях может различаться, но основные тенденции совпадают, а столбчатая структура и вертикально прорастающие дефекты (дислокации, нано- и микропоры) делают подавление вертикальных утечек более сложной задачей [12]. В реальных приборах утечки часто имеют смешанный (вертикально-латеральный) характер. Для приборов на проводящих подложках (например, кремниевых) вертикальные утечки являются наиболее критичными [2].

Типичные BAX структур с полуизолирующими слоями $\mathrm{GaN}$ показаны на рис. 1. Bсе BAX являются существенно нелинейными, при изменении толщины полу- 


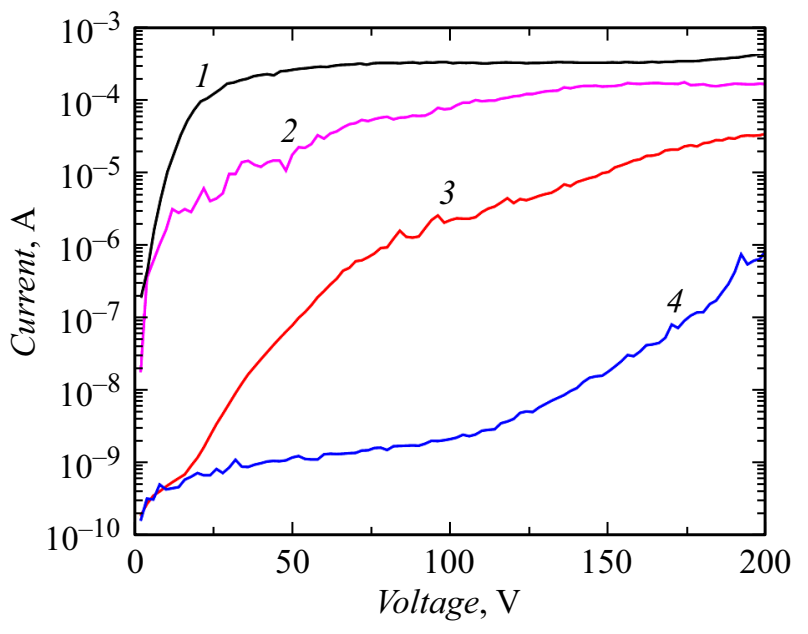

Рис. 1. ВАХ структур с разным легированием полуизолирующих слоев $\mathrm{GaN}$ толщиной $3 \mu \mathrm{m}$. Легирующая примесь (в скобках указана концентрация): 1 - нелегированный слой, $2-\mathrm{GaN}: \mathrm{C}\left(\sim 1.7 \cdot 10^{18} \mathrm{~cm}^{-3}\right), 3-\mathrm{Fe}\left(\sim 2 \cdot 10^{18} \mathrm{~cm}^{-3}\right), 4-$ $\mathrm{Fe}\left(\sim 2 \cdot 10^{18} \mathrm{~cm}^{-3}\right)+\mathrm{C}\left(\sim 1.7 \cdot 10^{18} \mathrm{~cm}^{-3}\right)$.

изолирующего слоя $\mathrm{GaN}$ в диапазоне $2-5 \mu \mathrm{m}$ или уровня легирования в диапазоне $(0.5-2) \cdot 10^{18} \mathrm{~cm}^{-3}$ величина утечек изменяется на много порядков. В настоящее время производится анализ данных и ставятся дополнительные эксперименты, результаты будут представлены в развернутой публикации. В настоящей работе мы хотим сконцентрироваться на одном наблюдении.

Величина тока утечки ожидаемо снижается с увеличением уровня легирования как углеродом, так и железом. Однако при слишком высокой концентрации примесей происходит существенное ухудшение морфологии поверхности полуизолирующих слоев. Для слоев $\mathrm{GaN}: \mathrm{C}$ начиная с концентрации $\sim(1-2) \cdot 10^{18} \mathrm{~cm}^{-3}$ на поверхности эпитаксиальных слоев формируются проколы (пинхолы, pinholes), отчетливо наблюдаемые в оптический микроскоп. При большей концентрации углерода их плотность настолько высока (рис. 2,a), что практически все области под контактами содержат пинхолы, что приводит к электрическому пробою при относительно низком напряжении. Хотя для отдельных контактов, попавших в области между пинхолами, токи утечки оказываются ниже, чем в структурах с меньшим уровнем легирования, подобные дефекты неприемлемы для приборных эпитаксиальных структур. По данным $\mathrm{ACM}$, легированные углеродом слои $\mathrm{GaN}$ не сильно отличались от нелегированных, однако концентрация ямок (nano-pits), частично декорирующих дислокации, была несколько выше (рис. 3, a). Образование пинхолов упоминается в литературе [7], хотя в целом авторы не акцентируют внимание на проблемах с морфологией поверхности в слоях $\mathrm{GaN}: \mathrm{C}$. Нарушения морфологии поверхности $\mathrm{GaN}$ при легировании железом, напротив, широко освещены в литературе. Типичным является формирование крупных (десятки-сотни микрометров) блоков, частично или полностью покрывающих поверх- ность эпитаксиальных слоев. В используемых нами технологических режимах вплоть до концентрации атомов железа $\sim 1.5 \cdot 10^{18} \mathrm{~cm}^{-3}$ поверхность GaN остается гладкой на всех масштабах. Однако дальнейшее увеличение уровня легирования приводит к резкому изменению характера роста с формированием выраженной блочной структуры (рис. 2,b), при этом поверхность блоков остается атомно-гладкой (рис. $3, b)$. Более того, выходы дислокаций не декорированы ямками. Очевидно, что наблюдаемая крупно-блочная структура эпитаксиальных слоев малопригодна для формирования приборов, хотя изолирующие характеристики таких слоев остаются весьма высокими (рис. 1).

Таким образом, как для $\mathrm{GaN}: \mathrm{C}$, так и для $\mathrm{GaN}: \mathrm{Fe}$ улучшение изолирующих свойств ограничено формированием дефектов. Вероятно, эти проблемы можно решить оптимизацией условий эпитаксиального роста. Однако мы предложили и проверили другой подход. Формирующиеся дефекты морфологии при избыточном уровне легирования $\mathrm{GaN}$ магнием и железом похожи. Для $\mathrm{GaN}: \mathrm{Mg}$ показано, что причиной является подавление нормального роста и доминирование латерального [13]. В то же время известно, что легирование

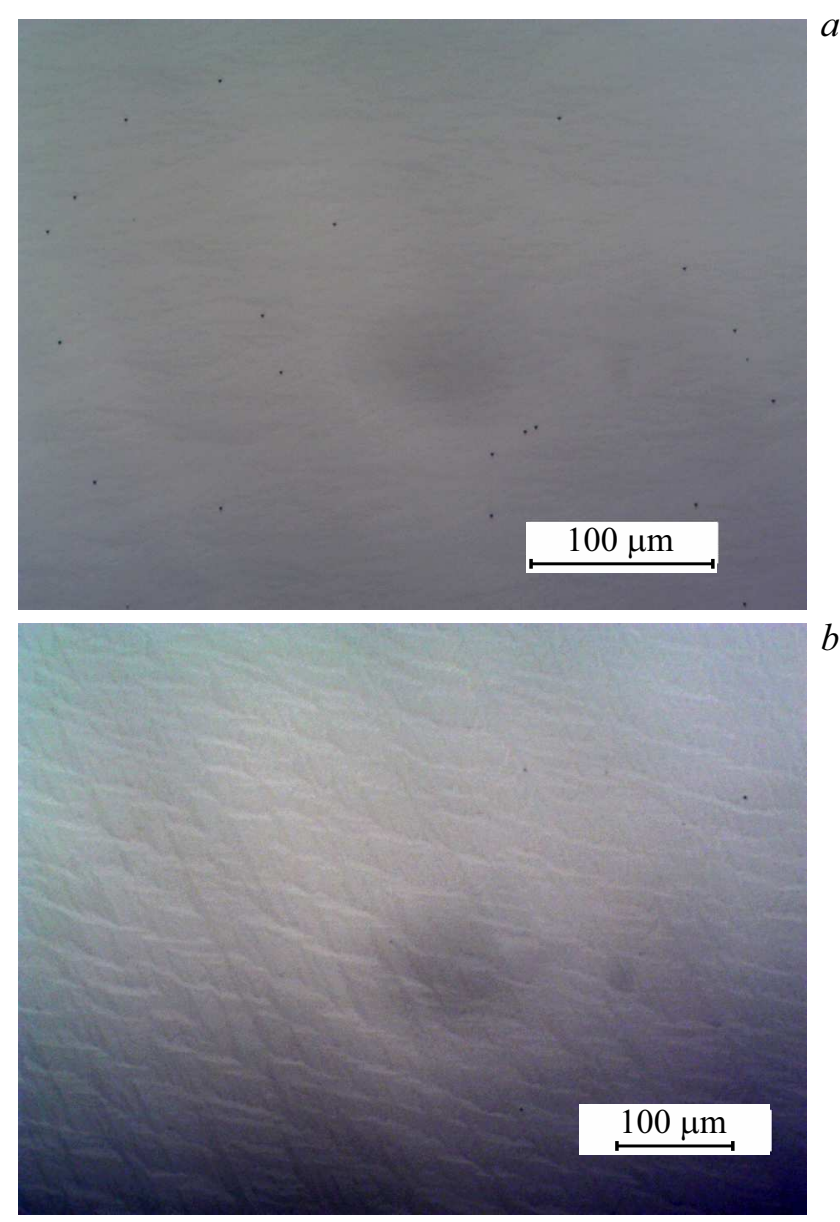

Рис. 2. Оптические микрофотографии эпитаксиальных слоев: $a-\mathrm{GaN}: \mathrm{C}\left(\sim 3 \cdot 10^{18} \mathrm{~cm}^{-3}\right)$, плотность пинхолов на образце от $1.5 \cdot 10^{4} \mathrm{~cm}^{-2}$ (на приведенной фотографии) до $2.5 \cdot 10^{5} \mathrm{~cm}^{-2} ; b-\mathrm{GaN}: \mathrm{Fe}\left(\sim 2 \cdot 10^{18} \mathrm{~cm}^{-3}\right)$. 

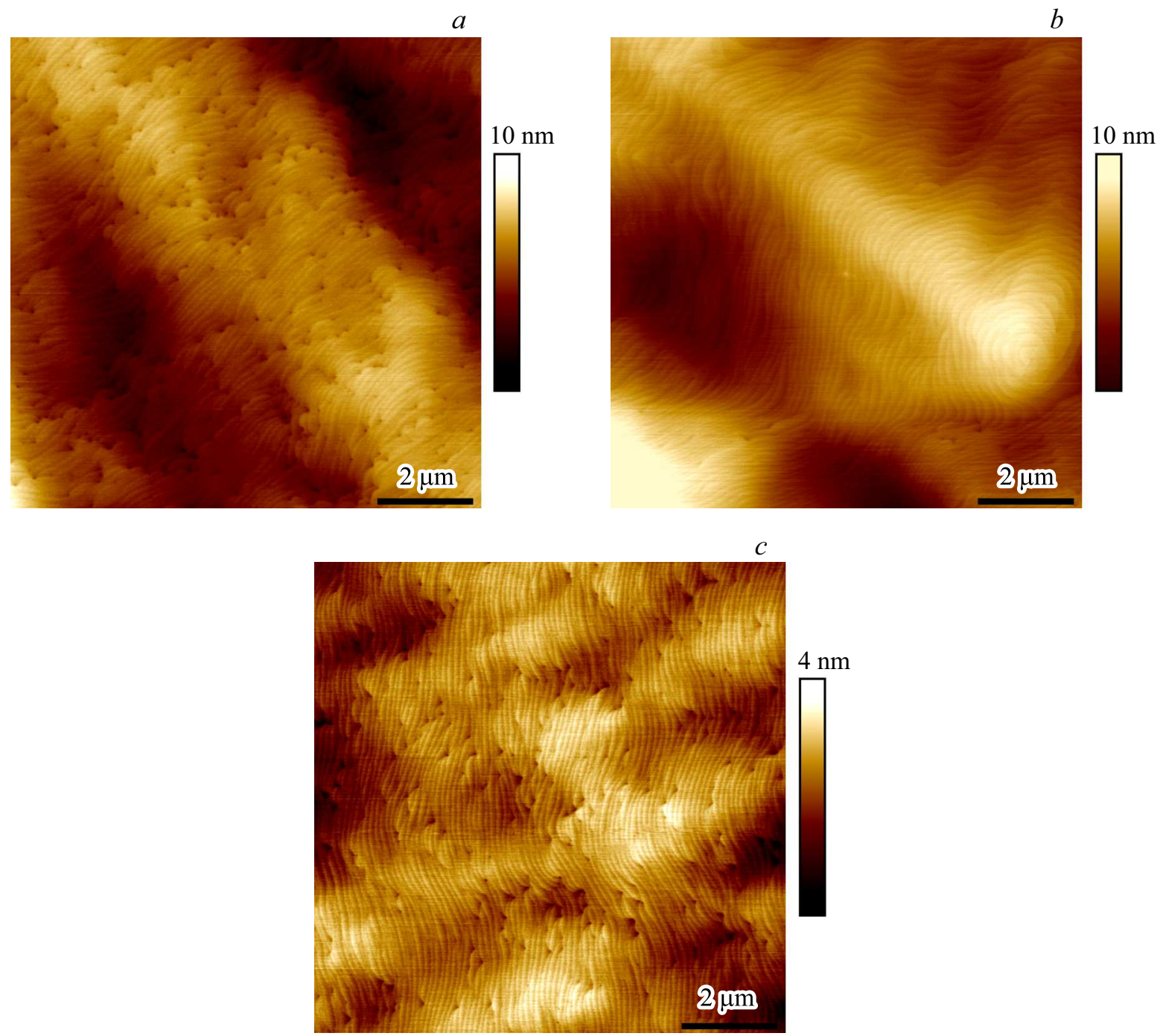

Рис. 3. Морфология поверхности легированных эпитаксиальных слоев $\mathrm{GaN}: a-\mathrm{GaN}: \mathrm{C}\left(\sim 1.7 \cdot 10^{18} \mathrm{~cm}^{-3}\right), b-\mathrm{GaN}: \mathrm{Fe}$ $\left(\sim 2 \cdot 10^{18} \mathrm{~cm}^{-3}\right), c-\mathrm{Fe}\left(\sim 2 \cdot 10^{18} \mathrm{~cm}^{-3}\right)+\mathrm{C}\left(\sim 1.7 \cdot 10^{18} \mathrm{~cm}^{-3}\right)$.

углеродом затрудняет срастание кристаллитов $\mathrm{GaN}$ на начальном этапе эпитаксиального роста [11], что можно связать с подавлением латеральной компоненты скорости роста. Можно ожидать компенсацию нежелательных влияний углерода и железа на характер роста $\mathrm{GaN}$ при их совместной подаче. Обоснованность этих предположений нуждается в проверке (например, изучении влияния углерода и железа на анизотропию скоростей роста при селективной эпитаксии). Однако совместное легирование $\mathrm{GaN}$ углеродом и железом позволило нам сформировать сильнолегированные высокоомные эпитаксиальные слои с совершенной морфологией.

Как показано на рис. 1, утечки в слое $\mathrm{GaN}:(\mathrm{Fe}, \mathrm{C})$ много меньше, чем при индивидуальном легировании. Еще предстоит выяснить, связано ли это с простым увеличением суммарной концентрации примесей или важно именно совместное легирование. При наблюдении в оптический микроскоп на поверхности слоев $\mathrm{GaN}:(\mathrm{Fe}, \mathrm{C})$ не обнаружено никакого рельефа. Нако- нец, такие эпитаксиальные слои обладают даже меньшей шероховатостью поверхности, чем нелегированные (рис. 3,c). Декорирующие дислокации ямки формировались, как и в слоях $\mathrm{GaN}$ : C. Возможно, и эту особенность удастся подавить при изменении соотношения уровней легирования углеродом и железом.

Таким образом, мы показали, что совместное легирование $\mathrm{GaN}$ углеродом и железом позволяет снизить токи утечек при сохранении (и даже улучшении) морфологии поверхности эпитаксиальных слоев.

\section{Благодарности}

АСМ-исследования выполнены с использованием оборудования федерального ЦКП „Материаловедение и диагностика в передовых технологиях“.

Авторы благодарят П.Б. Родина за плодотворное обсуждение результатов. 


\section{Конфликт интересов}

Авторы заявляют, что у них нет конфликта интересов.

\section{Список литературы}

[1] Lampert M.A., Mark $P$. Current injection in solids. N.Y.-London: Academic Press, 1970. 354 p. [Ламперт M., Марк П. Инжекционные токи в твердых телах. М.: Мир, 1973. $416 \mathrm{c}$.]

[2] Song Ch., Yang X., Ji P., Tang J., Hu A., Feng Y., Lin W., Ge W., Yang Zh., Xu F., Shen B. // Superlatt. Microstruct. 2019. V. 128. P. 199-203. DOI: 10.1016/j.spmi. 2019.01.028

[3] Weimann N.G., Eastman L.F., Doppalapudi Dh., Ng H.M., Moustakas T.D. // J. Appl. Phys. 1998. V. 83. N 7. P. 36563659.

[4] Li X., Danielsson O., Pedersen H., Janzen E., Forsberg U. // J. Vac. Sci. Technol. B. 2015. V. 33. N 2. P. 021208. DOI: $10.1116 / 1.4914316$

[5] Lundin W.V., Sakharov A.V., Zavarin E.E., Kazantsev D.Yu., Ber B.Ya., Yagovkina M.A., Brunkov P.N., Tsatsulnikov A.F. // J. Cryst. Growth. 2016. V. 449. P. 108-113.

DOI: $10.1016 /$ j.jcrysgro.2016.06.002

[6] Lesnik A., Hoffmann M.P., Fariza A., Bläsing J., Witte H., Veit P., Horich F., Berger Ch., Hennig J., Dadgar A., Strittmatter A. // Phys. Status Solidi B. 2017. V. 254. N 8. P. 1600708. DOI: $10.1002 /$ pssb.201600708

[7] Tsuchiya T., Terano A., Mochizuki K. // Jpn. J. Appl. Phys. 2016. V. 55. N 5S. P. 05FE05. DOI: 10.7567/JJAP.55.05FE05

[8] Rudzinski M., Desmaris V., van Hal P.A., Weyher J.L., Hageman P.R., Dynefors K., Rodle T.C., Jos H.F.F., Zirath H., Larsen P.K. // Phys. Status Solidi C. 2006. V. 3. N 6. P. 22312236. DOI: $10.1002 /$ pssc.200565379

[9] Lei C., Haibo Y., Lijuan J., Quan W., Chun F., Hongling X., Cuimei W., Jiamin G., Bo Zh., Baiquan Li, Xiaoliang W., Zhanguo W. // J. Semicond. 2015. V. 36. N 10. P. 103002. DOI: $10.1088 / 1674-4926 / 36 / 10 / 103002$

[10] Лундин В.В., Сахаров А.В., Заварин Е.Е., Закгейм Д.А., Николаев А.Е., Брунков П.Н., Яговкина М.А., Цачульников А.Ф. // Письма в ЖТФ. 2018. Т. 44. В. 13. С. 51-58. DOI: 10.21883/PJTF.2018.13.46327.17310

[11] Лундин В.В., Заварин Е.Е., Брунков П.Н., Яговкина М.А., Сахаров А.В., Синицын М.А., Бер Б.Я., Казанцев Д.Ю., Цаиульников А.Ф. // Письма в ЖТФ. 2016. Т. 42. В. 10. C. $85-91$.

[12] Fariza A., Lesnik A., Neugebauer S., Wieneke M., Hennig J., Bläsing J., Witte H., Dadgar A., Strittmatter A. // J. Appl. Phys. 2017. V. 122. N 2. P. 025704. DOI: $10.1063 / 1.4993180$

[13] Лундин В.В., Сахаров А.В., Заварин Е.Е., Синицын М.А., Николаев А.Е., Михайловский Г.А., Брунков П.Н., Гончаров В.В., Бер Б.Я., Казаниев Д.Ю., Цаиульников А.Ф. // ФТП. 2009. Т. 43. В. 7. С. $996-1001$. 